\title{
Costs and benefits of multiple resistance to insecticides for Culex quinquefasciatus mosquitoes
}

\author{
Claire Berticat*1, Julien Bonnet ${ }^{2}$, Stéphane Duchon², Philip Agnew ${ }^{3}$, \\ Mylène Weill ${ }^{1}$ and Vincent Corbel ${ }^{* 2}$
}

Address: ${ }^{1}$ Institut des Sciences de l'Evolution, UM2, CNRS ; Equipe Génétique de l'Adaptation, Université Montpellier 2, C.C. 065 , 34095 Montpellier, France, ${ }^{2}$ Laboratoire de Lutte contre les Insectes Nuisibles, Institut de Recherche pour le Développement, 911 Avenue Agropolis (BP 64501), 34394 Montpellier, France and ${ }^{3}$ Génétique et Evolution des Maladies Infectieuses, UMR 2724 CNRS-IRD, 911 Avenue Agropolis (BP 64501), 34394 Montpellier, France

Email: Claire Berticat* - claire.berticat@univ-montp2.fr; Julien Bonnet - bonnet@mpl.ird.fr; Stéphane Duchon - duchon@mpl.ird.fr; Philip Agnew - agnew@mpl.ird.fr; Mylène Weill - mylene.weill@univ-montp2.fr; Vincent Corbel* - corbel@mpl.ird.fr

* Corresponding authors

Published: 8 April 2008

BMC Evolutionary Biology 2008, 8:104 doi:10.1/86/147|-2/48-8-104
Received: 20 November 2007

Accepted: 8 April 2008

This article is available from: http://www.biomedcentral.com/I47I-2I48/8/I04

(c) 2008 Berticat et al; licensee BioMed Central Ltd.

This is an Open Access article distributed under the terms of the Creative Commons Attribution License (http://creativecommons.org/licenses/by/2.0), which permits unrestricted use, distribution, and reproduction in any medium, provided the original work is properly cited.

\begin{abstract}
Background: The evolutionary dynamics of xenobiotic resistance depends on how resistance mutations influence the fitness of their bearers, both in the presence and absence of xenobiotic selection pressure. In cases of multiple resistance, these dynamics will also depend on how individual resistance mutations interact with one another, and on the xenobiotics applied against them. We compared Culex quinquefasciatus mosquitoes harbouring two resistance alleles ace- $I^{R}$ and $K d r^{R}$ (conferring resistance to carbamate and pyrethroid insecticides, respectively) to mosquitoes bearing only one of the alleles, or neither allele. Comparisons were made in environments where both, only one, or neither type of insecticide was present.
\end{abstract}

Results: Each resistance allele was associated with fitness costs (survival to adulthood) in an insecticide-free environment, with the costs of ace- $I^{R}$ being greater than for $K d r^{R}$. However, there was a notable interaction in that the costs of harbouring both alleles were significantly less than for harbouring ace- $I^{R}$ alone. The two insecticides combined in an additive, synergistic and antagonistic manner depending on a mosquito's resistance status, but were not predictable based on the presence/absence of either, or both mutations.

Conclusion: Insecticide resistance mutations interacted to positively or negatively influence a mosquito's fitness, both in the presence or absence of insecticides. In particular, the presence of the $K d r^{R}$ mutation compensated for the costs of the ace- $I^{R}$ mutation in an insecticide-free environment, suggesting the strength of selection in untreated areas would be less against mosquitoes resistant to both insecticides than for those resistant to carbamates alone. Additional interactions suggest the dynamics of resistance will be difficult to predict in populations where multiple resistance mutations are present or that are subject to treatment by different xenobiotics. 


\section{Background}

Resistance to xenobiotics (antibiotics, insecticides, herbicides, etc...) is a problem limiting our ability to control organisms of a medical or economic importance. Multiple resistance, where organisms harbour separate mutations conferring resistance against more than one type of xenobiotic, poses an even greater problem. Furthermore, the number of cases documenting multiple resistance are increasing in frequency and involve a broad range of target organisms, including; viruses [1], bacteria [2], fungi [3], plants [4], and insects [5].

While little can prevent the emergence of resistance, short of stopping xenobiotic use, it should be possible to manage resistance in target populations by regulating how, when, and which xenobiotics are used. To do so, it is important to understand the evolutionary dynamics of resistance in both the presence and absence of xenobiotic selection pressure. This is because the extent to which a target population experiences these two types of environment will have a strong influence on the frequency of resistance and the rate at which it changes. For example, migration of susceptible and resistant individuals between treated and untreated areas influences spatial and temporal variations in the frequency of insecticide resistance alleles in populations of the peach-potato aphid Myzus persicae, [6-8] and Culex pipiens mosquitoes $[9,10]$. In each case, resistance alleles provide a fitness benefit to their bearers in the presence of a particular insecticide and can rapidly increase in frequency within populations. However in the absence of insecticide pressure, these resistance alleles are often associated with fitness costs that lead to them decreasing in frequency as resistant individuals are out-competed by susceptible rivals. For example, resistant individuals have been found to have lower mating success [11], be more susceptible to natural enemies $[12,13]$, or more prone to mortality during over-wintering [14]. However, there are some counterexamples where resistant individuals show a gain in their fitness relative to susceptible rivals in untreated areas. The traits involved include greater mating success $[15,16]$, and being less susceptible to the costs of natural enemies [12]. Thus it is important to identify traits that might be affected by resistance alleles and contexts in which they may influence fitness.

Far less information is available to estimate the dynamics of multiple resistance where resistance to more than one type of xenobiotic is conferred by the presence of resistance alleles at more than one locus. This situation is potentially more complex as resistance alleles could interact with one another to affect the fitness of their bearers, and these interactions could depend on the environmen- tal context determined by the presence/absence of one or more xenobiotic. Indeed, there is evidence from natural populations of mosquitoes that the frequency of doublyresistant individuals in untreated areas depart from Hardy-Weinberg expectations, indicating that alleles at different loci in these populations do interact with one another to affect the fitness of their bearers [17,18], and available data suggests a similar pattern may be occurring in aphids [6]. In addition, it is known that the efficacy of a xenobiotic can depend on the presence of other xenobiotics in the environment, such that the combined activity of two xenobiotics is greater (synergistic) or less (antagonistic) than expected based on the sum of activity for each compound separately [19]. Furthermore, whether two xenobiotics act synergistically or antagonistically can depend on the presence or absence of a particular resistance allele in the target individual, as has been found for carbamate and pyrethroid activity against Culex quinquefasciatus mosquitoes with or without the ace- $1^{R}$ allele at the ace-1 locus $[20,21]$. Hence, the evolutionary dynamics of multiple resistance are open to modification by interactions among alleles at different loci within the organism, interactions involving alleles and toxins in the environment, and interactions among toxins in the environment. Identifying these interactions and how they influence the fitness of multiply resistant organisms could provide useful information for operational strategies of resistance management and throw light on the physiological processes underlying them.

In the following article, we investigated the fitness effects of two insecticide resistance alleles, ace- $1^{R}$ and $K d r^{R}$, in four strains of $C$. quinquefasciatus that differed in harbouring only one resistance allele (either ace $-1^{R}$ or $K d r^{R}$ ), both alleles, or neither allele (Table 1). These mutations confer resistance to carbamate and pyrethroid insecticides, respectively. As an important vector of West Nile virus in North America [22], and a major vector of bancroftian filariasis in Africa [23], C. quinquefasciatus is frequently subject to control by insecticides, including the two mentioned above. The two resistance alleles involved in this study are present in natural mosquito populations, and some populations harbour both mutations [24,25]. Thus, multiple resistance is a potential problem in these populations.

Fitness estimates for resistance alleles, including any potential interactions among them, can vary according to the genetic background in which they are expressed $[26,27]$, and on the environmental conditions in which they are measured $[28,29]$. To control for the first factor, the two resistance alleles involved in this study were separately backcrossed into a common and susceptible genetic background provided by the SLAB strain of $C$. quinquefasciatus [30]. The doubly-resistant strain was 
Table I: Description of strain resistance genotypes. Genotypic description of each strain at the ace- $I$ and $K d r$ loci. Insecticide resistance alleles are in bold. All strains are homozygous at both loci.

\begin{tabular}{ccc}
\hline Strains $^{\mathrm{a}}$ & ace- $/$ allele & $K d r$ allele \\
\hline SLAB & $a c e-I^{S}$ & $K d r^{S}$ \\
SR & $a c e-I^{R}$ & $K d r^{S}$ \\
BC & $a c e-I^{S}$ & $K d r^{R}$ \\
BCSR & $a c e-I^{R}$ & $K d r^{R}$ \\
\hline
\end{tabular}

a Insecticide resistance alleles are in bold. All strains are homozygous at both loci

derived by backcrossing the two singly-resistant strains (see Methods for full details). Hence, differences between strains could be directly attributed to the expression of resistance alleles in a standard genetic environment. Measurements of fitness were performed in standardised laboratory conditions that differed only in the presence/ absence of one or both insecticides, thereby minimising other potentially confounding sources of genotype-byenvironment interactions.

\section{Results}

Fitness costs associated with resistance alleles

There were costs associated with insecticide resistance in an insecticide-free environment (Figure 1). Strains differed in the average probability of female emergence ( minimal model; Strain, $F[3,74]=17.226, p<0.001, r^{2}=$ 0.41 , with a Tukey-Kramer HSD test finding emergence from the susceptible SLAB strain to be significantly greater than for the three resistant strains. The same test also found the emergence of strains BC and BCSR to not be different, and that both were significantly greater than for strain SR. In other words, doubly-resistant females from strain BCSR, harbouring both ace- $1^{R}$ and $K d r^{R}$ alleles, were significantly more likely to reach adulthood than singlyresistant females of strain SR with only the ace- $1^{R}$ allele.

\section{Insecticide interactions}

The dose-effect curves for permethrin, carbosulfan and their mixtures on the mortality of adult female mosquitoes of each strain (SLAB, SR, BC and BCSR) are shown in Figure 2. For each strain, the dose-mortality relationships were sigmoidal. Mortality in control batches never exceeded $10 \%$. Median lethal doses for these relationships are listed in Table 2.

Figure 3 illustrates whether there was additive, synergistic or antagonistic activity of mixtures containing both insecticides. Diagonal lines connect doses of permethrin on the $x$-axis with doses of carbosulfan on the $y$-axis where each insecticide was equally efficient at killing mosquitoes when applied alone (isoboles $\mathrm{ED}_{10}, \mathrm{ED}_{50}$ and $\mathrm{ED}_{90}$ are

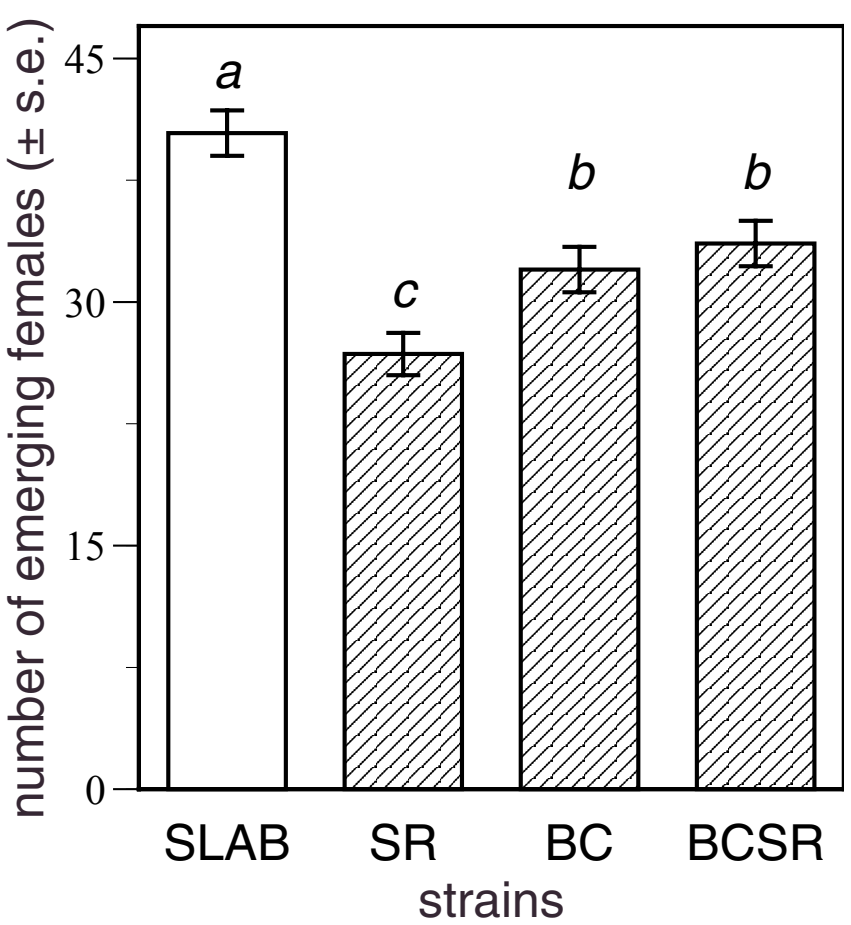

Figure I

Costs of resistance in an insecticide-free environment. The number of female mosquitoes emerging in an insecticide-free environment. Insecticide susceptible strain $S L A B$ is shown in an open column and the three resistant strains are shown in hatched columns. In two replicate experiments, there were nine or ten pots initially containing 100 larvae for each of the four strains. Different letters above columns indicate significant differences $(p<0.05)$ in female emergence as found by a Tukey-Kramer test (see text for details).

shown). The position of the matching data points relative to these lines indicates how much of each insecticide was required to achieve the same effect when insecticides were mixed at a ratio determined by their median-effect doses: data points above the line indicate antagonistic activity of the two insecticides, points close to the line indicate additive activity, while those below the line reveal synergistic activity of the two compounds.

The susceptible strain SLAB showed, a limited degree of synergy in activity, especially when the treatment doses applied induced $<80 \%$ mortality. That is, the mixture of insecticides was more potent or effective than would be expected if each had acted in an independent and additive manner. However, at higher doses inducing $>80 \%$ mortality, the two compounds acted in an additive fashion (Figure 3A). In contrast, the two insecticides acted antagonistically when applied to the carbamate-resistant strain SR, especially once $>25 \%$ of the mosquitoes were killed during assays (Figure 3B). Hence, the combination 

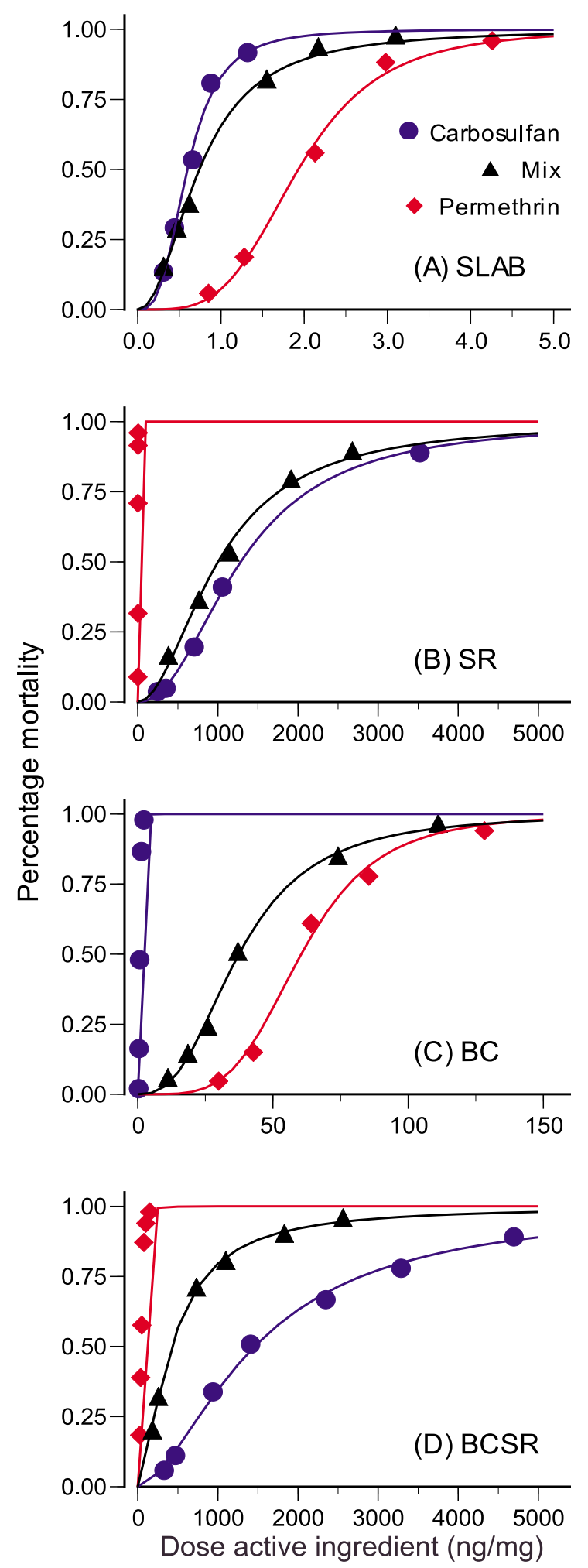

Figure 2

Dose-effect curves for insecticide activity. Dose-effect curves of permethrin, carbosulfan and their mixture on the four strains of mosquito.
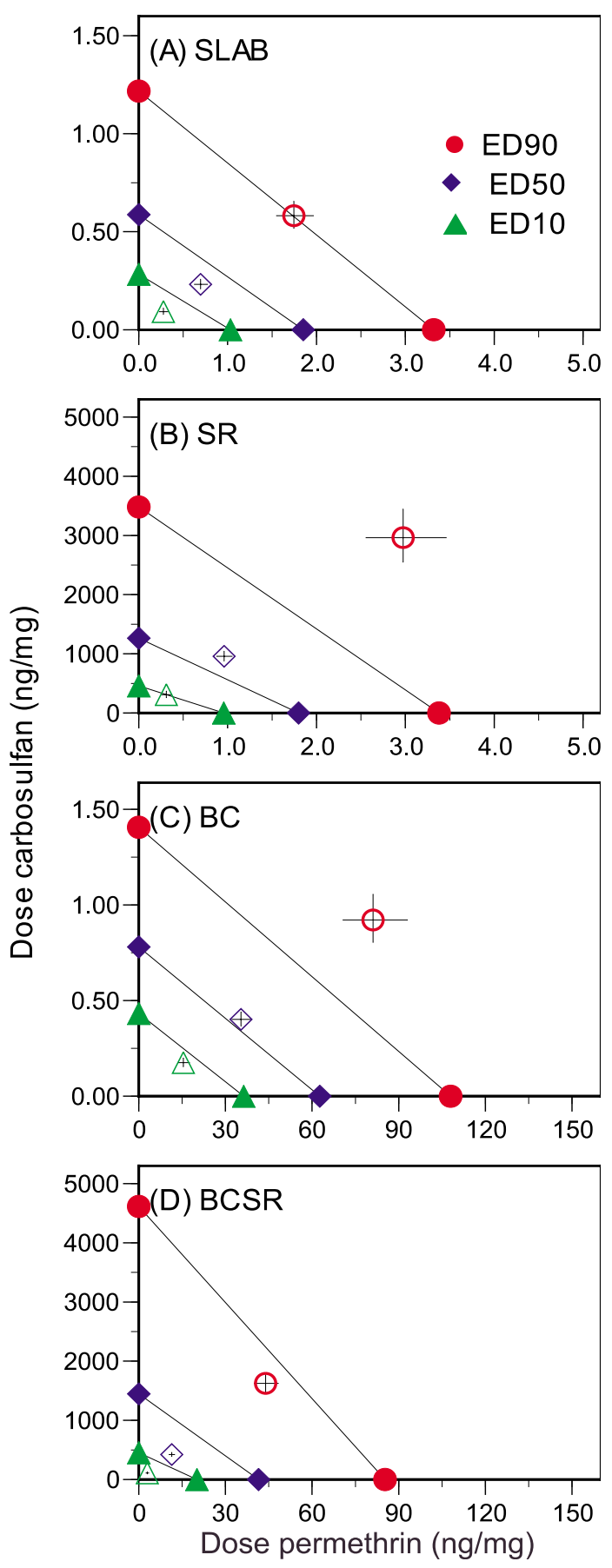

Figure 3

Isobolograms of insecticide activity. Diagonal lines connect doses of equally effective activity for each insecticide when applied alone. Open symbols are for the amount of each insecticide required for the same effect when the two are mixed together at a ratio based on their median-effect doses $( \pm 95 \%$ confidence intervals). Points above the matching line indicate antagonistic activity of the insecticides, close to the line indicates additivity of action, and those below the line indicate synergistic activity. 
Table 2: Median-lethal doses used. Median-lethal doses $\mathrm{ng} / \mathrm{mg}$ ( $\pm 95 \%$ confidence intervals) for mosquito strains tested with different insecticides and their mixture.

\begin{tabular}{|c|c|c|c|c|c|c|c|c|}
\hline Strain & & SLAB & & $S R$ & & $B C$ & & BCSR \\
\hline \multicolumn{9}{|l|}{ insecticide } \\
\hline Permethrin (P) & 1.85 & $(1.75-1.95)$ & 1.80 & $(1.7 I-1.89)$ & 62.65 & $(59.38-66.10)$ & 41.47 & $(39.56-43.47)$ \\
\hline Carbosulfan (C) & 0.59 & $(0.52-0.66)$ & 1264.00 & $(1166-1370)$ & 0.78 & $(0.68-0.90)$ & 1446.00 & $(1330-1572)$ \\
\hline Mix & 0.99 & $(0.90-1.08)$ & 982.00 & $(884-1084)$ & 37.56 & (34.97-40.39) & 438.00 & $(386-492)$ \\
\hline mix ratio $\mathrm{P}: \mathrm{C}$ & $3: 1$ & & $\mathrm{I}: 750$ & & $85: 1$ & & $\mathrm{I}: 35$ & \\
\hline \multicolumn{9}{|l|}{ regression coefficienta \pm (s.e.) } \\
\hline Permethrin & $3.76^{\mathrm{a}}$ & $(0.18)$ & $3.48^{\mathrm{a}}$ & $(0.15)$ & $4.04^{a}$ & $(0.22)$ & $3.05^{\mathrm{a}}$ & $(0.10)$ \\
\hline Carbosulfan & $3.01^{b}$ & $(0.16)$ & $2.17^{b}$ & $(0.07)$ & $3.73^{\mathrm{a}}$ & $(0.31)$ & $1.89 \mathrm{~b}$ & $(0.07)$ \\
\hline Mix & $2.95^{b}$ & $(0.22)$ & $2.69 c$ & $(0.22)$ & $3.53^{\mathrm{a}}$ & $(0.20)$ & $2.15^{c}$ & $(0.15)$ \\
\hline
\end{tabular}

a estimates within a column that differ in super-script letter are significantly different $(p<0.05)$

of insecticides was less efficient than would be expected had each acted separately in an additive fashion. A simple additive effect was found for the pyrethroid-resistant $\mathrm{BC}$ strain in the low to medium range of insecticide activity, while at high doses antagonistic behaviour was observed (Figure 3C). Finally, the doubly resistant strain BCSR, showed striking synergism between the pyrethroid and carbamate activity (Figure 3D) indicating the mix of insecticides was more efficient at killing mosquitoes than if each had acted additively.

\section{Discussion}

Evolutionary theory predicts that mutations of large phenotypic effect, such as resistance mutations, are likely to be costly to their bearers in environments where they were not selected [31,32]. We found costs associated with both resistance mutations in an insecticide-free environment (Figure 1). Significantly fewer females emerged as adults from resistant strains SR and BC in comparison to the susceptible control strain SLAB. These costs could be associated with how the resistance mutations influence the nervous system. In strain SR, the ace- $1^{R}$ mutation causes hyper-activity of nervous systems due to a modified acetylcholinesterase (AChE) that is less efficient at catalysing the breakdown of acetylcholine (ACh) bound to nicotinic receptors at the post-synaptic membrane [33]. In the field, fewer homozygotes of ace- $1^{R}$ were found than would be expected from the Hardy-Weinberg ratio, indicating reduced viability of these homozygotes $[17,18]$. Recent findings from studies on Drosophila melanogaster suggest these costs could directly arise from a reduced stability of the enzyme due to changes in its deacetylation [34]. In contrast, Lee et al. observed changes in the pharmacological and biophysical properties of sodium channels in Heliothis virescens moths with pyrethroid resistance due to a $K d r$ mutation [35]. These changes were found to cause sluggish neural activity in the absence of pyrethroids and were characterized by decreased cellular and behavioural excitability of sodium channels [35]. The Kdr mutation enhances closed-state inactivation of nerves, meaning that more stimulation is required before nerves fire and release ACh into the synaptic cleft in comparison with susceptible individuals [36].

The fitness of the BCSR strain harbouring both ace- $1^{R}$ and $K d r^{R}$ was of particular interest. Reduced female emergence, relative to the susceptible SLAB strain, showed there were costs of resistance for this strain. However, the costs of harbouring both resistance alleles were significantly less than for strain SR only harbouring the ace- $1^{R}$ mutation (Figure 1). We speculate that the relatively greater costs associated with a reduced efficiency of ACh degradation at the post-synaptic terminal (due to ace- $1^{R}$ ) could be partially compensated for by a more sluggish release of ACh at the pre-synaptic terminal (due to $K d r^{R}$ ). This hypothesis of how the two alleles interact at the functional level could be tested by electrophysiological examination of the synaptic activity of insects harbouring only one resistance allele (either ace- $1^{R}$ or $K d r^{R}$ ), both alleles, or neither allele.

The reduced costs experienced by strain BCSR relative to strain SR in an insecticide-free environment are noteworthy as they illustrate that one resistance allele can act as a compensatory mutation for another resistance allele, and both can be mutations of large effect. Our results would predict the addition of $K d r^{R}$, by mutation or recombination, to a genotype with ace- $1^{R}$ already present would reduce the strength of selection against $a c e-1^{R}$ in an insecticide-free environment. Thus not only would the strength of selection against $a c e-1^{R}$ be reduced in untreated populations, but this allele would remain for longer in untreated populations in mosquitoes with both resistance alleles and that were resistant to both carbamate and pyrethroid insecticides, rather than in mosquitoes only resistant to carbamates. Although this prediction can only strictly be applied to $C$. quinquefasciatus mosquitoes of the SLAB strain, the role of compensatory activity among resistance alleles on the evolution and control of multiple 
resistance warrants general investigation, as this experiment provides evidence that it can occur.

We also found evidence that resistance alleles interacted with one another in the presence of both insecticides. When mosquitoes were tested against mixtures of permethrin and carbosulfan, strain SLAB showed evidence for additive activity of the two insecticides at high doses (Figure 3A), while BC showed additive activity at low to medium doses (Figure 3C). In contrast, there was a synergy of activity at low doses when both insecticides were tested against SLAB (Figure 3A), but this effect was more striking for the doubly-resistant BCSR strain (Figure 3D). This latter result confirms previous studies involving the SLAB strain $[18,20]$, where these studies showed both insecticides complemented each other as both cause ACh to accumulate in synaptic clefts. Furthermore, at sufficiently high concentrations, ACh simulates the activity of muscarinic receptors $\mathrm{M} 2$ at the pre-synaptic terminal [37]. Simulation of these receptors inhibits further release of ACh into the synaptic cleft. This enhanced negative feedback inhibition of ACh release effectively shuts down neural activity and leads to the insect's death.

There was synergism in insecticide activity when applied to BCSR, but antagonism for strain SR (Figure 3B). We cannot currently explain this result. Although the mode of action for pyrethroids and carbamates against susceptible insects have described in detail $[38,39]$, it is less clear as to how they induce mortality when organisms harbour multiple resistance alleles. From a physiological point of view, point mutations in sodium channels and acetylcholinesterase are responsible for reduced insecticide sensitivity in several insect species $[17,34,36]$. Consequently, when the primary targets of insecticides become insensitive (as is the case for BCSR and SR), higher doses are required to achieve equivalent mortality and secondary target sites may be involved. In doing so, they add to the number of events influencing neuronal activity and the pathways by which insecticides can act and interact with one another, e.g., GABA receptor - ionophore complex or chloride channel and muscarinic receptors have been shown to be secondary target sites for pyrethroids and carbamates, respectively $[39,40]$. To our knowledge, the only publication investigating the functional costs of harbouring multiple resistance alleles was published by Bourguet et al. in 1997 [33]. In this article the authors showed AChE activity in the SR strain of $C$. quinquefasciatus was unaffected by the treatment of propoxur (a carbamate), even at doses of insecticides inducing $100 \%$ mortality. This lead to the suspicion that mortality of SR larvae was not due to AChE inhibition, but to the insecticide interacting with another target site, known as choline acetyltransferase, or ChAT, which is involved in ACh synthesis [41]. This hypothesis was supported by the behavioural abnormal- ity of moribund larvae due to a lack of ACh in the synapse and the fact that in vitro inhibition of ChAT activity was caused by doses of propoxur inducing mortality of the SR strain [33].

A greater understanding of the mechanisms involved in what determines positive or negative interactions of insecticide activity will require further toxicological and electrophysiological studies involving single- and multipleresistance alleles in appropriate environments where their effects can be directly compared and contrasted.

\section{Conclusion}

Our results show the resistance alleles ace- $1^{R}$ and $K d r^{R}$ interact with one another to influence the fitness of $C$. quinquefasciatus mosquitoes in a laboratory environment, and that they did so in both the presence and absence of insecticides. A particularly interesting, and potentially worrying, observation was that $K d r^{R}$ could compensate for the costs of ace- $1^{R}$ in an insecticide-free environment. This would predict selection against $a c e-1^{R}$ in untreated environments would be slower in mosquitoes resistant to both pyrethroid and carbamate insecticides, rather than just resistant to carbamates. More needs to be done to verify if this is an isolated interaction or if it more widely reflects how resistance alleles may interact. We also found a female mosquito's resistance status influenced whether mixtures of carbamate and pyrethroid insecticides had additive, synergistic or antagonistic activity. Overall these results suggest the evolutionary dynamics of resistance will be difficult to predict in populations where multiple resistance mutations are present or that are subject to treatment by different xenobiotics.

\section{Methods \\ Mosquito strains}

Four strains of C. quinquefasciatus were used; SLAB, SR, BC, and BCSR. They all share the same genetic background and cytoplasm, and only differ in their genotype at the ace-1 and $K d r$ loci. SLAB, the insecticide susceptible reference strain [30], is homozygous for susceptible alleles at both loci. SR is homozygous for the resistant allele ace- $1^{R}$ and for the susceptible allele $K d r^{S}$ and was introgressed into the genome of SLAB through 14 repeated generations of backcrossing [11]. BC is homozygous for the susceptible allele ace- $1^{S}$ and for the resistant allele $K d r^{R}$; BCSR is homozygous for resistant alleles at both loci (Table 1).

The BC strain was derived from the B-KPER strain [20] whose genome was introgressed into that of SLAB through 13 repeated generations of backcrossing. At each generation, a discriminating dose of permethrin $\left(3 \mathrm{mg} \mathrm{l}^{-1}\right)$, a pyrethroid, was applied to select for resistant heterozygotes at the $K d r$ locus, and surviving females were crossed with SLAB males. During the last generation of backcross- 
ing, surviving males were crossed with SLAB females in order to introduce the SLAB cytoplasm into the introgressed strains. Finally, homozygosity of the strains for these resistance alleles was verified by analysing parents using the molecular test of Weill et al.. [17] BCSR was derived from the cross between SR and BC strains. Homozygosity of this strain for resistant alleles at the $K d r$ and ace-1 loci was achieved by the F3 generation, as confirmed by the molecular test of Martinez-Torres et al. [42] and Weill et al. [17], respectively. To insure differences in resistance and life-history traits between the four strains were not due to maternal effects, each strain was reared for at least two generations in standard laboratory conditions without insecticide selection, before experiments began.

\section{Fitness costs of resistance alleles}

We measured the cost of the $K d r^{R}$ and ace- $1^{R}$ resistance alleles on the probability of female mosquitoes reaching adulthood. The oviposition of the four parental strains was synchronised and nine or ten groups of 100 firstinstar larvae for each strain were transferred to pots containing $200 \mathrm{ml}$ of tap water and $0.1 \mathrm{~g}$ of yeast. These pots were randomly distributed on the same table in a single room with temperature and light controlled $\left(22^{\circ}\right.$ to $25^{\circ} \mathrm{C}$, with a $12 \mathrm{~L}: 12 \mathrm{D}$ photoperiod). From, three days post-hatching, water and food were changed daily (food ad libitum) and the number and sex of emerging adults was recorded. This experiment was performed twice and involved a total of 3900 larvae in each experiment.

The number of adult females emerging from each pot was analysed and did not require transformation to meet requirements for parametric analysis. We focussed on females as only adult females were involved in the insecticide trials described below, and because female survival to adulthood is much more epidemiologically important than male survival. Female emergence was analysed with a fully factorial analysis of variance (ANOVA) with strain (SLAB, SR, BC, BCSR) as a fixed nominal factor and replicate experiment as a random nominal factor. Models were simplified when F-tests found no significant difference between full and reduced models. In each case, ShaprioWilk $W$ goodness of fit tests found residuals were not significantly different from a normal distribution (analyses not shown). Analyses for the number of emerging males or total adult emergence gave similar results, and adult sex ratios did not depart from a 1:1 ratio (analyses not shown). Analyses were performed using JMP software (V. 5.1.2, SAS Institute 2004).

\section{Analysis of insecticide interactions}

Topical applications were used to study the interactions between pyrethroids and carbamates because they allow an accurate estimation of the intrinsic toxicity of an insecticide by excluding all other effects linked to a mosquito's behaviour [43]. First, topical solutions were prepared by dissolving technical grades of permethrin (96\% cis:trans ratio 25:75, Bayer CropScience, Villefranche-sur-Saone, France) and/or carbosulfan (90.81\%, FMC Corporation, Princetown, New Jersey) in acetone. For each insecticide and the mixtures, five to eight doses were used to provide a range of mortality from $0 \%$ to $100 \%$. Two to five dayold, non-blood-fed females of each strain were anaesthetised by extended contact with carbon dioxide and then deposited on a chilled plate $\left(4^{\circ} \mathrm{C}\right)$ to maintain anaesthesia during manipulation. Fifty females were used for each dose of insecticide. A volume of $0.1 \mu \mathrm{l}$ insecticide solution (at the required concentration) was deposited on the upper part of the pronotum of females using a micro-capillary tube. Fifty females that received a volume of $0.1 \mu \mathrm{l}$ of pure acetone served as controls. After each test, females were transferred to covered plastic cups and provided with a $10 \%$ sugar solution on cotton wool and held for 24 hours at $27^{\circ} \mathrm{C}$ and $80 \%$ relative humidity. Mortality rates were recorded 24 hours after the tests. The data were expressed in nanograms of insecticide per milligram of wet female weight and each test was done in triplicate using different batches and generations of mosquitoes.

Data were analysed according to the method of Chou and Talalay [44] using Calcusyn ${ }^{\circledR}$ software [45]. This software provides an accurate estimation of the median-effect doses (analogous to the more familiar $\mathrm{LD}_{50}$ values) $\pm 95 \%$ confidence intervals for each insecticide and their mixture. The median effect plot states that:

$$
\log (F a / F u)=m \times \log (D x / D m)
$$

where $F a$ and $F u$ are the proportions of mosquitoes affected and unaffected, respectively, by the dose $D x . m$ represents the slope of the regression line, and Dm the dose required to produce the median effect.

For each strain, a binary mixture of permethrin and carbosulfan was used at a constant ratio determined by the ratio of their median-effect doses. At the ratios chosen, both insecticides would be expected to make an equal contribution towards the mortality of each mosquito strain. The existence of interactions between the two insecticides was determined by the Isobologram model of [44], adapted to the analysis of multiple drugs.

\section{Authors' contributions}

Each author contributed towards the design of the experiments. MW, JB, and SD conducted the experiments. $\mathrm{CB}$ and PA analyzed the data. CB, PA, MW and VC wrote the paper. All authors read and approved the final manuscript. 


\section{Acknowledgements}

We are grateful to Yannis Michalakis and anonymous reviewers for helpful comments on earlier versions of the manuscript. Clotilde Bernard and Sandra Unal are thanked for their technical assistance. We thank the "Ministère Français de la Recherche" for funding this work as part of the PAL+ programme into malaria and associated communicable diseases in developing countries. This work was also financed in part by the ANR Morevol SanteEnvironnement (Ministère délégué à la Recherche). The authors were funded by the Centre National de la Recherche Scientifique (CNRS) and the Institut de Recherche pour le Développement (IRD). Contribution 2008028 of the Institut des Sciences de l'Evolution de Montpellier (UMR CNRS 5554). All authors read and approved the final version of the manuscript.

\section{References}

I. Tamalet C, Fantini J, Tourres C, Yahi N: Resistance of HIV-I to multiple antiretroviral drugs in France: a 6-year survey (1997-2002) based on an analysis of over 7000 genotypes. Aids 2003, I 7( I 6):2383-2388.

2. Carraminana J, Rota C, Agustin I, Herrera A: High prevalence of multiple resistance to antibiotics in Salmonella serovars isolated from a poultry slaughterhouse in Spain. Veterinary Microbiology 2004, I 04(I-2): I 33-139.

3. Somani J, Bhullar VB, Workowski KA, Farshy CE, Black CM: Multiple drug-resistant Chlamydia trachomatis associated with clinical treatment failure. Journal of Infectious Diseases 2000, | 8 | (4): | 42|- | 427.

4. Walsh MJ, Powles SB, Beard BR, Porter SA: Multiple-herbicide resistance across four modes of action in wild radish (Raphanus raphanistrum). Weed Science 2004, 52(I):8-13

5. Corbel V, N'Guessan R, Brengues C, Chandre F, Djogbenou L, Martin $T$, Akogbeto A, Hougard JM, Rowland M: Multiple insecticide resistance mechanisms in Anopheles gambiae and Culex quinquefasciatus from Benin, West Africa. Acta Tropica 2007, I 0 I (3):207-216

6. Anstead JA, Mallet J, Denholm I: Temporal and spatial incidence of alleles conferring knockdown resistance to pyrethroids in the peach-potato aphid, Myzus persicae (Hemiptera : Aphididae), and their association with other insecticide resistance mechanisms. Bulletin of Entomological Research 2007 97(3):243-252.

7. Fenton B, Malloch G, Woodford JAT, Foster SP, Anstead J, Denholm I, King L, Pickup J: The attack of the clones: tracking the movement of insecticide-resistant peach-potato aphids Myzus persicae (Hemiptera : Aphididae). Bulletin of Entomological Research 2005, 95(5):483-494.

8. Foster SP, Harrington R, Dewar AM, Denholm I, Devonshire AL Temporal and spatial dynamics of insecticide resistance in Myzus persicae (Hemiptera : Aphididae). Pest Management Science 2002, 58(9):895-907.

9. Labbe $\mathrm{P}$, Lenormand $\mathrm{T}$, Raymond M: On the worldwide spread of an insecticide resistance gene: a role for local selection. J Evolution Biol 2005, I 8(6): |47|- | 484

10. Lenormand T, Bourguet D, Guillemaud T, Raymond M: Tracking the evolution of insecticide resistance in the mosquito Culex pipiens. Nature 1999, 400(6747):86I-864.

II. Berticat C, Boquien G, Raymond M, Chevillon C: Insecticide resistance genes induce a mating competition cost in Culex pipiens mosquitoes. Genetical Research 2002, 79(I):4I-47.

12. Agnew P, Berticat C, Bedhomme S, Sidobre C, Michalakis Y: Parasitism increases and decreases the costs of insecticide resistance in mosquitoes. Evolution 2004, 58(3):579-586.

13. Foster SP, Woodcock CM, Williamson MS, Devonshire AL, Denholm I, Thompson R: Reduced alarm response by peach-potato aphids, Myzus persicae (Hemiptera : Aphididae), with knockdown resistance to insecticides $(k d r)$ may impose a fitness cost through increased vulnerability to natural enemies. Bulletin of Entomological Research 1999, 89(2): I33-138.

14. Foster SP, Harrington R, Devonshire AL, Denholm I, Devine G], Kenward MG, Bale JS: Comparative survival of insecticide-susceptible and resistant peach-potato aphids, Myzus persicae (Sulzer) (Hemiptera: Aphididae), in low temperature field trials. Bulletin of Entomological Research 1996, 86(I): I7-27.
15. Arnaud L, Haubruge E: Insecticide resistance enhances male reproductive success in a beetle. Evolution 2002, 56( I 2):2435-2444.

16. Arnaud L, Brostaux Y, Assie LK, Gaspar C, Haubruge E: Increased fecundity of malathion-specific resistant beetles in absence of insecticide pressure. Heredity 2002, 89(6):425-429.

17. Weill M, Malcolm C, Chandre F, Mogensen K, Berthomieu A, Marquine $M$, Raymond $M$ : The unique mutation in ace- I giving high insecticide resistance is easily detectable in mosquito vectors. Insect Molecular Biology 2004, I 3(I): I-7.

18. Asidi AN, Guessan RN, Koffi AA, Curtis CF, Hougard JM, Chandre F, Corbel V, Darriet F, Zaim M, Rowland MW: Experimental hut evaluation of bednets treated with an organophosphate (chlorpyrifos-methyl) or a pyrethroid (lambdacyhalothrin) alone and in combination against insecticide-resistant Anopheles gambiae and Culex quinquefasciatus mosquitoes. Malaria Journal 2005, 4:

19. Tallarida RJ: The interaction index: a measure of drug synergism. Pain 2002, 98(I-2): I63-168.

20. Corbel V, Chandre F, Darriet F, Lardeux F, Hougard JM: Synergism between permethrin and propoxur against Culex quinquefasciatus mosquito larvae. Medical and Veterinary Entomology 2003, I7(2): $158-164$

21. Corbel V, Raymond M, Chandre F, Darriet F, Hougard JM: Efficacy of insecticide mixtures against larvae of Culex quinquefasciatus (Say) (Diptera : Culicidae) resistant to pyrethroids and carbamates. Pest Management Science 2004, 60(4):375-380.

22. Girard $Y A$, Klingler KA, Higgs S: West Nile virus dissemination and tissue tropisms in orally infected Culex pipiens quinquefasciatus. Vector-Borne and Zoonotic Diseases 2004, 4(2): 109-122.

23. Maxwell CA, Mohammed K, Kisumku U, Curtis CF: Can vector control play a useful supplementary role against bancroftian filariasis? Bulletin of the World Health Organization 1999, 77(2): | 38- | 43 .

24. Chandre F, Darriet F, Doannio JMC, Riviere F, Pasteur N, Guillet P: Distribution of organophosphate and carbamate resistance in Culex pipiens quinquefasciatus (Diptera : Culicidae) in West Africa. Journal of Medical Entomology 1997, 34(6):664-67I.

25. Chandre F, Darriet F, Darder M, Cuany A, Doannio JMC, Pasteur N, Guillet P: Pyrethroid resistance in Culex quinquefasciatus from West Africa. Medical and Veterinary Entomology 1998 , I 2(4):359-366.

26. Mckenzie JA, Whitten MJ, Adena MA: The Effect of Genetic Background on the Fitness of Diazinon Resistance Genotypes of the Australian Sheep Blowfly, Lucilia cuprina. Heredity 1982, 49(AUG): I-9.

27. Schrag SJ, Perrot V, Levin BR: Adaptation to the fitness costs of antibiotic resistance in Escherichia coli. Proceedings of the Royal Society of London Series B-Biological Sciences 1997, 264(I386): | 287-| $29 \mid$.

28. Mckenzie JA: Selection at the Diazinon Resistance Locus in Overwintering Populations of Lucilia cuprina (the Australian Sheep Blowfly). Heredity 1994, 73:57-64.

29. Purrington $C B$, Bergelson J: Exploring the physiological basis of costs of herbicide resistance in Arabidopsis thaliana. American Naturalist 1999, I 54:S82-S91.

30. Georghiou GP, Metcalf RL, Gidden FE: Carbamate resistance in mosquitoes: selection of Culex pipiens fatigans Wied. (=Culex quinquefasciatus) for resistance to Baygon. Bulletin of the World Health Organisation 1966, 35(5):691-807.

31. Fisher RA: The Genetic Theory of Natural Selection. Dover 1958.

32. Orr HA: The population genetics of adaptation: The distribution of factors fixed during adaptive evolution. Evolution 1998 , 52(4):935-949.

33. Bourguet $D$, Raymond $M$, Berrada $S$, Fournier $D$ : Interaction between acetylcholinesterase and choline acetyltransferase: an hypothesis to explain unusual toxicological responses. Pesticide Science 1997, 5 I (3):276-282.

34. Shi MA, Lougarre A, Alies C, Fremaux I, Tang ZH, Stojan J, Fournier $D$ : Acetylcholinesterase alterations reveal the fitness cost of mutations conferring insecticide resistance. BMC Evolutionary Biology 2004, 4:.

35. Lee D, Park Y, Brown TM, Adams ME: Altered properties of neuronal sodium channels associated with genetic resistance to pyrethroids. Molecular Pharmacology 1999, 55(3):584-593. 
36. Vais $\mathrm{H}$, Williamson MS, Goodson SJ, Devonshire AL, Warmke JW, Usherwood PNR, Cohen CJ: Activation of Drosophila sodium channels promotes modification by deltamethrin - Reductions in affinity caused by knock-down resistance mutations. Journal of General Physiology 2000, I I 5(3):305-3I 8.

37. Corbel V, Stankiewicz M, Bonnet J, Grolleau F, Hougard JM, Lapied B: Synergism between insecticides permethrin and propoxur occurs through activation of presynaptic muscarinic negative feedback of acetylcholine release in the insect central nervous system. Neurotoxicology 2006, 27(4):508-5I9.

38. Corbett JR: Biochemical Mode of Pesticides. London-New York, Academic Press; 1974.

39. Raymond-Delpech V, Matsuda K, Sattelle BM, Rauh JJ, Sattelle DB: Ion channels: molecular targets of neuroactive insecticides. Invertebrate Neuroscience 2005, 5(3): I I9-133.

40. Beukel I, Dijcks FA, Vanderheyden P, Vauquelin G, Oortgiesen M: Differential Muscarinic Receptor Binding of Acetylcholinesterase Inhibitors in Rat Brain, Human Brain and Chinese Hamster Ovary Cells Expressing Human Receptors. Journal of Pharmacology and Experimental Therapeutics 1997, 28 I (3): I I 3-I I I 9.

41. Pitman RM: Transmitter substances in insects: a review. Comp Gen Pharmacol I97I, 2(7):347-37I.

42. Martinez-Torres D, Chandre F, Williamson MS, Darriet F, Berge JB, Devonshire AL, Guillet P, Pasteur N, Pauron D: Molecular characterization of pyrethroid knockdown resistance (kdr) in the major malaria vector Anopheles gambiae S.S. Insect Molecular Biology 1998, 7(2): 179- 184.

43. WHO: Guidelines for testing mosquito adulticides intended for Indoor Residual Spraying (IRS) and Insecticide Treated Nets (ITNs). Geneva 3rd edition. 2006. WHO/CDS/NTD/ WHOPES/GCDDP/2006.2003

44. Chou TC, Talalay P: Quantitative analysis of dose-effect relationships: the combined effects of multiple drugs or enzyme inhibitors. Adv Enzyme Regul 1984, 22:27-55.

45. Chou TC, Hayball MP: CalcuSyn: Windows software for dose effect analysis. BIOSOFT, Cambridge, UK; 1996.

Publish with Bio Med Central and every scientist can read your work free of charge

"BioMed Central will be the most significant development for disseminating the results of biomedical research in our lifetime. "

Sir Paul Nurse, Cancer Research UK

Your research papers will be:

- available free of charge to the entire biomedical community

- peer reviewed and published immediately upon acceptance

- cited in PubMed and archived on PubMed Central

- yours - you keep the copyright
BioMedcentral 